\title{
Tree-Ring Amplification of the Early Nineteenth-Century Summer Cooling in Central Europe ${ }^{a}$
}

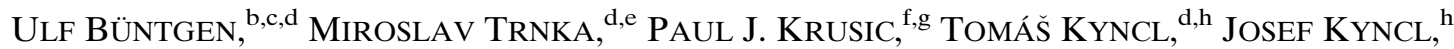 \\ JÜrg LUTERBACHER, ${ }^{\mathrm{i}}$ EDUARDO ZORITA, ${ }^{\mathrm{j}}$ FrEDRIK CHARPENTIER LJUNGQVIST, ${ }^{\mathrm{k}, \mathrm{l}}$ \\ Ingeborg Auer, ${ }^{\mathrm{m}}$ Oliver Konter, ${ }^{\mathrm{n}}$ LEA SCHNEIDER, ${ }^{\mathrm{n}}$ Willy TEgEl, ${ }^{\circ}$ Petr ŠTĚPÁNeK, ${ }^{\mathrm{d}}$

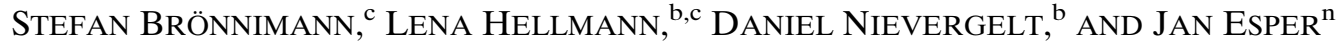 \\ ${ }^{\mathrm{b}}$ Swiss Federal Research Institute WSL, Birmensdorf, Switzerland \\ ${ }^{\mathrm{c}}$ Oeschger Centre for Climate Change Research, Bern, Switzerland \\ ${ }^{\mathrm{d}}$ Global Change Research Centre AS CR v.v.i., Brno, Czech Republic \\ ${ }^{\mathrm{e}}$ Institute of Agriculture Systems and Bioclimatology, Mendel University in Brno, Brno, Czech Republic \\ ${ }_{\mathrm{f}}^{\mathrm{f}}$ Department of Physical Geography, Stockholm University, Stockholm, Sweden \\ ${ }^{\mathrm{g}}$ Navarino Environmental Observatory, Messinia, Greece \\ ${ }^{\mathrm{h}}$ Moravian Dendro-Labor, Brno, Czech Republic \\ i Department of Geography, Justus Liebig University, Giessen, Germany \\ ${ }^{\mathrm{j}}$ Institute for Coastal Research, Helmholtz Zentrum, Geesthacht, Germany \\ ${ }^{\mathrm{k}}$ Bolin Centre for Climate Research, Stockholm University, Stockholm, Sweden \\ ${ }^{1}$ Department of History, Stockholm University, Stockholm, Sweden \\ ${ }^{\mathrm{m}}$ Central Institute for Meteorology and Geodynamics (ZAMG), Vienna, Austria \\ ${ }^{\mathrm{n}}$ Department of Geography, Johannes Gutenberg University, Mainz, Germany \\ ${ }^{\circ}$ Institute for Forest Growth (IWW), University of Freiburg, Freiburg, Germany
}

(Manuscript received 6 October 2014, in final form 16 March 2015)

\begin{abstract}
Annually resolved and absolutely dated tree-ring chronologies are the most important proxy archives to reconstruct climate variability over centuries to millennia. However, the suitability of tree-ring chronologies to reflect the "true" spectral properties of past changes in temperature and hydroclimate has recently been debated. At issue is the accurate quantification of temperature differences between early nineteenth-century cooling and recent warming. In this regard, central Europe (CEU) offers the unique opportunity to compare evidence from instrumental measurements, paleomodel simulations, and proxy reconstructions covering both the exceptionally hot summer of 2003 and the year without summer in 1816. This study uses 565 Swiss stone pine (Pinus cembra) ring width samples from high-elevation sites in the Slovakian Tatra Mountains and Austrian Alps to reconstruct CEU summer temperatures over the past three centuries. This new temperature history is compared to different sets of instrumental measurements and state-of-the-art climate model simulations. All records independently reveal the coolest conditions in the 1810s and warmest after 1996, but the ring width-based reconstruction overestimates the intensity and duration of the early nineteenth-century summer cooling by approximately $1.5^{\circ} \mathrm{C}$ at decadal scales. This proxy-specific deviation is most likely triggered by inflated biological memory in response to reduced warm season temperature, together with changes in radiation and precipitation following the Tambora eruption in April 1815. While suggesting there exists a specific limitation in ring width chronologies to capture abrupt climate perturbations with increased climate system inertia, the results underline the importance of alternative dendrochronological and wood anatomical parameters, including stable isotopes and maximum density, to assess the frequency and severity of climatic extremes.
\end{abstract}

${ }^{\text {a }}$ Supplemental information related to this paper is available at the Journals Online website: http://dx.doi.org/10.1175/JCLI-D-14-00673.s1.

Publisher's Note: This article was revised on 1 December 2015 to correct an error in the funding information that appeared in the Acknowledgments section.

Corresponding author address: Ulf Büntgen, Swiss Federal Research Institute WSL, Zürcherstrasse 111, CH-8903, Birmensdorf, Switzerland. E-mail: buentgen@wsl.ch

DOI: 10.1175/JCLI-D-14-00673.1 


\section{Introduction}

It is well accepted that tree-ring chronologies can provide annually resolved and absolutely dated temperature and hydroclimatic reconstructions over centuries to millennia (Frank et al. 2010; Masson-Delmotte et al. 2013; and references therein). These records represent the backbone of high-resolution paleoclimatology, offering a long-term perspective of Earth's climate.

The ability of tree-ring-based proxy records to accurately capture the "true" spectrum of past natural and recent anthropogenic climate change, including externally forced and internally modulated stochastic and quasiperiodic climate variability (Hegerl et al. 2007; Esper et al. 2012), has recently been challenged (Bunde et al. 2013; Franke et al. 2013; Tingley et al. 2014). Two possible explanations for how tree-ring-based reconstructions may under- or overestimate high- and low-frequency variations in climate are the site-specific climate sensitivity of tree growth (Fritts 1976) and the method of tree-ring standardization used to "detrend" raw measurements (Melvin and Briffa 2008, 2014). Different detrending techniques can dramatically affect the properties of a chronology through their ability to preserve or remove specific frequency bands from a time series (Esper et al. 2003, 2005).

At the same time, a dispute concerning a potentially limited sensitivity to cold temperatures in trees growing near the tree line, causing missing rings after very large stratospheric volcanic eruptions (Anchukaitis et al. 2012; Mann et al. 2012a,b; D'Arrigo et al. 2013; Esper et al. 2013b; Mann et al. 2013), has raised questions not only about the reliability of tree-ring chronologies as highresolution climate proxy archives but more generally their credibility as precise dating tools (Büntgen et al. 2014).

Strong tropical volcanic eruptions can trigger abrupt perturbations in Earth's climate system with subsequent effects on human societies (Stothers 1999, 2000; Robock 2000; de Boer and Sanders 2002; Cole-Dai 2010). Such eruptions represent a unique opportunity to evaluate the climatological fingerprint of a rapid climate change in proxy-based reconstructions (Hegerl et al. 2003, 2011; Fischer et al. 2007; Wahl et al. 2014). In turn, so-called detection and attribution studies aim to provide a better understanding of climate models' sensitivity to external forcings and/or internal modulations (Barnett et al. 1999; Hegerl et al. 1996; Merlis et al. 2014). Explosive volcanism injects sulfate aerosols into the stratosphere, scattering incoming solar radiation and absorbing outgoing infrared radiation (Cole-Dai 2010). As a consequence, Earth's surface is cooled while the lower stratosphere is warmed (Robock 2000). Precise estimates of the climate response to a given volume, height, and chemical composition of an eruption cloud depend on our degree of understanding the physical connection between volcanic eruptions and atmospheric processes (Cole-Dai 2010; Esper et al. 2013a,b). The relatively short residence time of volcanic aerosols in the stratosphere limits the duration of direct volcanic impacts on regional- and large-scale temperature and precipitation dynamics, lasting only a few years succeeding an eruption (Robock 2000; Stenchikov et al. 2002; Fischer et al. 2007; Cole-Dai 2010; Merlis et al. 2014). However, recent results from coupled ocean-atmosphere model simulations indicate that strong tropical volcanic eruptions can initiate decadal-scale dynamical responses in the climate system, thereby extending climate recovery beyond the short-lived radiative forcing effect (Miller et al. 2012; Zanchettin et al. 2013a,b). The impacts of volcanic aerosols generated in the stratosphere on tropospheric cloud formation, precipitation, and the diurnal temperature range are still poorly documented (Auchmann et al. 2012, 2013; Wegmann et al. 2014; Brugnara et al. 2015), neither from observations nor from the transient climate sensitivity in forced models (Shindell 2014). Little information is available on the influence of volcanic eruptions on regional modifications of the global water cycle and atmospheric circulation patterns (Fischer et al. 2007; Anchukaitis et al. 2010; Joseph and Zeng 2011; Timmreck 2012). This deficit emerges from the fact that complex, and localized, seasonal responses to volcanism may exist (Shindell et al. 2004; Trigo et al. 2009; Wahl et al. 2014), such as modulations of the monsoon system and other large-scale teleconnections (Wahl et al. 2014; Wegmann et al. 2014), which are not yet fully quantified. Hydroclimatic behavior following large volcanic eruptions may abate or exacerbate the negative effects of reduced summer temperatures on ecosystem functioning and productivity (Briffa et al. 1998; Anchukaitis et al. 2012).

At the same time, it is still debated if enhanced photosynthetic activity under increased diffuse sunlight may compensate for some of the cooling-related growth reductions (Farquhar and Roderick 2003; Gu et al. 2003; Krakauer and Randerson 2003). For example, the slight drop in the growth rate of atmospheric $\mathrm{CO}_{2}$ following the 1991 Mount Pinatubo (Luzon) eruption could be explained by an increase in forest net primary production (NPP) if indeed forests use diffuse light more efficiently than direct light for photosynthesis. Thus, the fraction of diffuse sunlight in the years following an eruption, because of scattered volcanic sulfur aerosols, can have a dynamical effect on terrestrial ecosystem productivity and the global carbon cycle (Gu et al. 2003).

Given our limited understanding of plant physiological behavior under (rapid) climate change (Körner 2006), the pulselike nature of posteruptive summer cooling in tandem with possibly augmented photosynthetic activity due to diffuse light provides optimal conditions for assessing 
the growth response of high- and midlatitude forest trees to abrupt negative summer temperature deviations (Fischer et al. 2007; Esper et al. 2013a,b). The so-called biological memory, inherent to all trees and partly reflecting their complex plant physiology (and possibly ecosystem biogeochemistry), describes the dependency of annual ring formation on previous year circumstances (Frank et al. 2007). Although lagged responses are particularly strong during periods of feeble growth conditions (Büntgen et al. 2006), it remains somewhat unclear if and how tree-ring-based temperature reconstructions overestimate the amplitude and duration of postvolcanic cooling (Esper et al. 2013a,b; Tingley et al. 2014). A detailed examination of possible reconstruction error may depend on having sufficient overlap between annually resolved tree-ring records and a credible set of instrumental measurements during episodes of large volcanic eruptions (Frank et al. 2007). Additional independent mechanistic understanding can emerge from climate model simulations (Gómez-Navarro et al. 2012, 2013, 2014, 2015; Schimanke et al. 2012; Gutiérrez et al. 2013), which should subsequently be considered in high-resolution paleoclimatology (PAGES 2k Consortium 2014). The availability of extant instrumental, proxy, and model data from central Europe (CEU), in the first half of the nineteenth century, satisfies all these conditions.

To assess the level of coherency between tree-ring deviations and climate swings following large (mainly tropical) volcanic eruptions, we developed two independent Swiss stone pine (Pinus cembra) ring width chronologies from high-elevation, near-tree line sites in the Slovakian Tatra Mountains and Austrian Alps. After combining these datasets, the new compilation is used to reconstruct interannual-to-centennial-long changes in CEU summer temperature. Our proxy-based temperature history is compared with paleoclimatic evidence of externally forced model simulations from phase 5 of CMIP (CMIP5)/PMIP phase 3 (PMIP3) experiments (Taylor et al. 2012) as well as with long instrumental measurements of temperature, precipitation, cloud cover, and solar radiation. Attention is paid to the detection of potentially differing responses to increased volcanic activity in the early nineteenth century.

The early nineteenth century is of particular interest as it includes the largest annually dated geographically assigned eruption of the past millennium, Tambora in April 1815 (Stothers 1984; Oppenheimer 2003). The Tambora eruption produced the strongest simulated summer cooling in the CMIP5/PMIP3 models back to AD 850 (Masson-Delmotte et al. 2013) and probably altered the hydrological cycle over parts of the North Atlantic/European (EU) sector (Fischer et al. 2007; Luterbacher and Pfister 2015), particularly over the Iberian Peninsula (Trigo et al. 2009). Further intensification of the early nineteenth-century volcanic response emerges from exceptionally low solar activity during the Dalton Minimum between about 1790 and 1830 (Lean et al. 1995; Wagner and Zorita 2005; Steinhilber et al. 2012). While focusing on the various limitations of tree-ring width chronologies to properly capture the effects of abrupt climate perturbations, our discussion also emphasizes the potential of wood anatomical characteristics, such as cell dimension and lignin concentration, to more accurately capture changes in frequency and severity of temperature extremes.

\section{Data and methods}

A total of 565 tree-ring width (TRW) samples (5-mm cores) were collected in the Austrian Alps and the Slovakian Tatra Mountains. All samples are from Swiss stone pines (Pinus cembra) growing in recently protected, and thus with significant likelihood to be relatively undisturbed, tree line ecotones in western-central Austria $(>2100 \mathrm{~m}$ MSL; 410 samples) and northern Slovakia (>1500 m MSL; 155 samples). The level of disturbance during historical times, however, remains unknown. Site selection resulted in a near-optimal spatial representation of the species' natural distribution across CEU (Fig. 1a). Standard wood anatomical techniques were applied to subsamples from both regions to quantify anomalous TRW depression in the early nineteenth century (Fig. 1b and Fig. S1a in the supplemental material). After cutting the sample surfaces with a core microtome (Gärtner et al. 2014), the resulting microslides were double stained with safranin and astra blue (Büntgen et al. 2014), rinsed with ethanol, and finally embedded in Canadian balsam. Digital images were taken with an Olympus ColorView IIIu camera fitted to a Leica MZ12 microscope at 0.8 times magnification.

To guarantee the development of two independent TRW chronologies, all measured series from Austria and Slovakia were cross dated and standardized separately at the country level. Data from living trees in the Alps and Tatra Mountains span the periods 1417-2008 and 16872012, respectively (Fig. S1a). Their expressed population signals (EPS; Wigley et al. 1984) are above the 0.85 quality threshold back to 1700 (Fig. S1b). The EPS statistic, computed over 30-yr windows, lagged by $15 \mathrm{yr}$, represents a summary measure of TRW coherency describing how well a chronology, based on a finite number of samples, estimates the theoretical population from which it was drawn (Briffa et al. 2013). The mean segment length of the Alps and Tatra Mountains samples is 191 and $154 \mathrm{yr}$, respectively (Fig. S2 in the supplemental material), and their average growth rates (AGR) are almost identical at 1.13 and $1.14 \mathrm{~mm} \mathrm{yr}^{-1}$.

Various detrending techniques were applied to remove the nonclimatic, so-called biological age, trend from the raw TRW measurement series (Fritts 1976; Linderholm et al. 2014), while preserving high-to-low-frequency temperature 


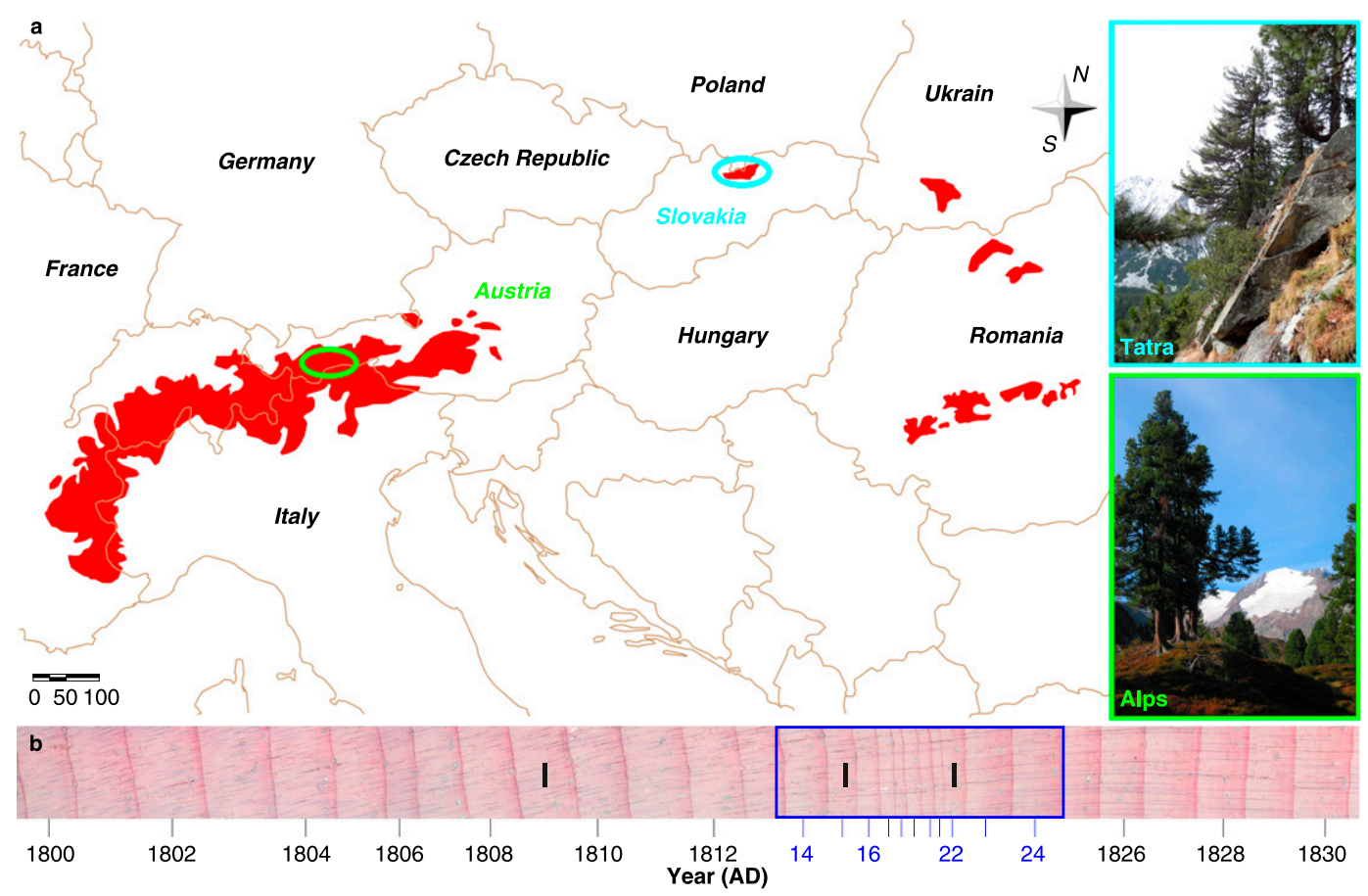

FIG. 1. (a) Natural Swiss stone pine (Pinus cembra) distribution across CEU (red), together with the geographical location of the two sampling regions in the western Austrian Alps $\left(\sim 47^{\circ} \mathrm{N}\right.$ and $\left.12^{\circ} \mathrm{E} ; \sim 2300 \mathrm{~m} \mathrm{MSL}\right)$ and northern Slovakian Tatra Mountains ( $\sim 49^{\circ} \mathrm{N}$ and $\left.20^{\circ} \mathrm{E} ; \sim 1500 \mathrm{~m} \mathrm{MSL}\right)$. (b) Wood anatomical microsection highlights the growth depression in a pine sample from the Tatra Mountains (CE32b) following the Tambora eruption [Lesser Sunda Islands, Indonesia, 10 Apr 1815, volcanic explosivity index (VEI) 7 and an estimated tephra volume of $160 \times$ $10^{9} \mathrm{~m}^{3}$ ]. However there are no growth responses visible following the Galunggung (Java, Indonesia, 8 Oct 1822, VEI 5 and an estimated tephra volume of $1 \times 10^{9} \mathrm{~m}^{3}$ ) and the unknown eruption in 1809 (Guevara-Murua et al. 2014, and references therein). The vertical black lines refer to the three eruptions.

variability that occurred during the last centuries, when CEU summer temperatures started to increase from exceptionally cold conditions in the early nineteenth century to the most recent warming at the onset of the third millennium (Luterbacher et al. 2004; Büntgen et al. 2006, 2011; PAGES 2k Consortium 2013). Cubicspline smoothing with $50 \%$ frequency response cutoff at 150 and $300 \mathrm{yr}$ (SPL; Cook and Peters 1981), negative exponential and straight line functions (Neg1 and Neg2), as well as the regional curve standardization (RCS; Esper et al. 2003) were applied using the most recent version of the ARSTAN software (Cook and Krusic 2005). Consideration of all five detrending methods supports the assessment of interannual-tomultidecadal, and possibly even lower, frequency information on centennial time scales. The corresponding index values were calculated either as ratios or residuals after power transformation (PT; Cook and Peters 1997) between the nontransformed or transformed measurements and their corresponding curve fits. The final TRW chronologies for each country (Austria and Slovakia) were produced using biweight robust means where temporal variance changes in the chronologies were further stabilized with respect to fluctuations in sample size (Osborn et al. 1997).

The 10 Austrian TRW chronologies share a significant fraction of common high-to-low-frequency variability (Fig. S3 in the supplemental material). Their interseries correlation (Rbar) is 0.86 (1723-2008). A statistically similar coherency is found between all Slovakian chronologies, reaching an Rbar of 0.93 over the period during which records are replicated by at least 10 series. Although temporally varying (Fig. S3c), the agreement between all TRW chronologies from the Alps and Tatra Mountains (Rbar = 0.45), together with their shared sensitivity to June-August (JJA) temperatures (Büntgen et al. 2007, 2011), permits combining the two regional mean chronologies into a single CEU Pinus cembra chronology (details on the site-specific TRW behavior and the effect of different calibration periods are provided in Figs. S3 and S5 in the supplemental material, with statistics being summarized in Table 1). TRW data from the Alps and Tatra Mountains were also separately utilized to reconstruct JJA temperatures to assess their coherency (Table 1).

The 10 slightly different, but not fully independent, instrumental datasets of monthly and spatially resolved 


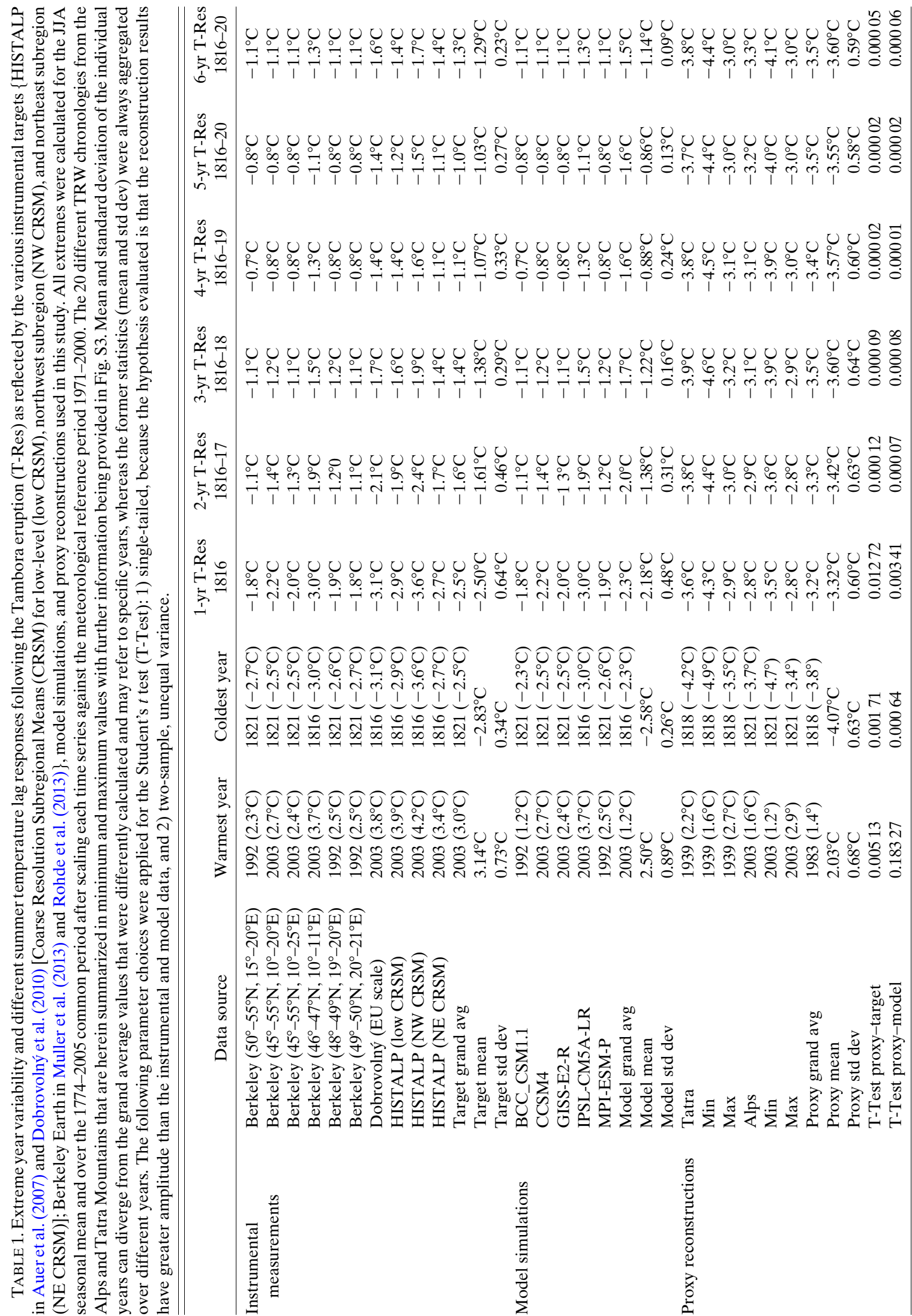




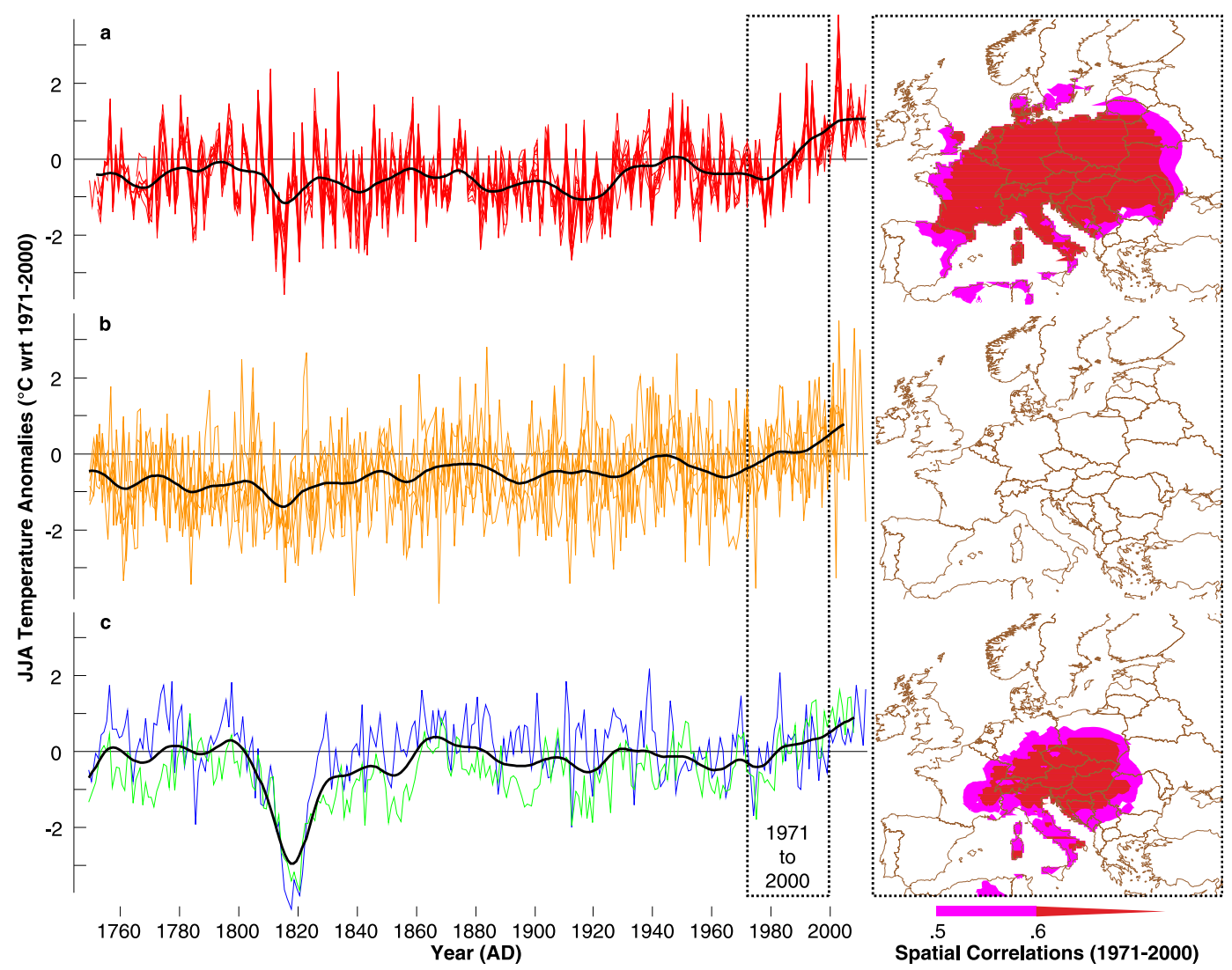

FIG. 2. On the left-hand side, time series of (a) 10 instrumental (thin red lines), (b) 5 simulated (thin orange lines), and (c) 2 reconstructed (green and blue lines indicate the Alps and Tatra Mountains, respectively) CEU summer temperatures; that is, each time series was scaled against the 1971-2000 JJA reference period (see also Table 1 for details), together with their corresponding means after $20 \mathrm{yr}$ low-pass filtering (black curves; cubic-spline smoothing with $50 \%$ frequency response cutoff at $20 \mathrm{yr}$ ). Right-hand side maps reveal spatial Pearson correlation patterns of the unfiltered mean of the (a) 10 instrumental, (b) 5 simulated, and (c) 2 reconstructed CEU summer temperatures records [i.e., their linear relationships with high-resolution $\left(0.25^{\circ} \times 0.25^{\circ}\right)$ gridded JJA landmass temperatures from E-OBSv10.0 (Haylock et al. 2008, updated)]. All correlations were calculated over the 1971-2000 calibration period and only values exceeding $r>0.5$ are plotted.

gridded summer temperatures, including the Historical Instrumental Climatological Surface Time Series of the Greater Alpine Region (HISTALP) (Auer et al. 2007), Dobrovolný et al. (2010), and Berkeley Earth (http:// berkeleyearth.org/data/; Muller et al. 2013; Rohde et al. 2013), were compiled for comparison with the new CEU Swiss stone pine TRW records (Table 1, Fig. 2a) as well as the site-specific reconstructions (more information on the different instrumental datasets is provided in Fig. S4 in the supplemental material). Extending back to 1774, and representing slightly different spatial domains between the $45^{\circ}-55^{\circ} \mathrm{N}$ and $10^{\circ}-21^{\circ} \mathrm{E}$, these climate records correlate with each other at 0.86 (Rbar; 1774-2007). The interseries correlation of the 10 instrumental records between 1971 and 2000 is 0.95 . A simple scaling approach was used to fit the new TRW record against CEU summer temperatures; both the mean and variance of the TRW chronology were adjusted to current year JJA temperatures of the 1971-2000 period (Fig. S5). This procedure, the simplest among calibration techniques, is less prone to variance underestimation (as direct regression) and overestimation (as indirect regression) (Esper et al. 2005; Bürger et al. 2006; Christiansen 2011). Since our study explicitly focuses on the relative differences between measured, simulated, and reconstructed year-to-year temperature changes during the early nineteenth century, the calibration interval, which represents $30 \mathrm{yr}$ of modern climate variability, could have been replaced by any other period.

Mean JJA summer temperatures were extracted over CEU between $45^{\circ}-55^{\circ} \mathrm{N}$ and $10^{\circ}-25^{\circ} \mathrm{E}$ from five simulations used in CMIP5 (Taylor et al. 2012) for the period 850-2005: BCC_CSM1.1, CCSM4, GISSE2-R, IPSL-CM5A-LR, and MPI-ESM-P (Table 1, expansions of model name acronyms are available at 
http://www.ametsoc.org/PubsAcronymList; Fig. 2b). Although the CMIP5 project aimed to run all models under comparable conditions, their external solar, volcanic, and land-use forcings are not exactly the same (Schmidt et al. 2011, 2012). In this regard the limited size of the model ensemble is considered a guidance of the structural and forcing uncertainty. A full consideration of the structural uncertainty and a proper definition of the "model space" is a question that has not been resolved in climate research yet. Hence, for the time being, we have to accept the limitations inherent in model ensembles of opportunity.

The mean of the two TRW chronologies from the Alps and Tatra Mountains, the average of the 10 instrumental datasets, as well as the mean of the five model simulations are expressed as JJA temperature anomalies from the 1971-2000 mean climatology (Table 1, Fig. 2). Spatial Pearson correlation fields were calculated over the 19712000 period to assess the linear relationship between the reconstructed proxy, measured instrumental, and simulated model means against high-resolution $\left(0.25^{\circ} \times 0.25^{\circ}\right)$ gridded JJA European observations of landmass temperatures (E-OBSv10.0; Haylock et al. 2008, updated). Temporal changes in the coherency among time series and persistence structure were assessed using 31-yr moving Pearson correlation coefficients and first-order autocorrelation functions. Midtropospheric $500-\mathrm{hPa}$ geopotential height anomaly fields (Z500; Luterbacher et al. 2002) for each summer between 1815 and 1822 were calculated as departures from the JJA climatology of 1971-2000 over the North Atlantic/EU sector. The Z500 reconstructions are not only based on early instrumental observations of pressure but also on temperature and precipitation data. Hence, there is partial circularity when utilizing the spatially reconstructed Z500 fields to explain anomalies of temperature and cloudiness across the North Atlantic/EU sector. Details on the spatial field reconstructions, their quality, and underlying predictor data can be found in Luterbacher et al. (2002).

Monthly resolved CEU cloud cover data (the percentage of sky covered by clouds) were selected from two homogenized stations in the HISTALP project: Milano and Torino, both in northern Italy, spanning the 17632012 period (Auer et al. 2007). Located at the southern margin of the research area, these two stations are the closest containing continuous data back to the early nineteenth century. Monthly precipitation totals were averaged over the entire HISTALP low-elevation network (www.zamg.ac.at/histalp/). For an in-depth climatological assessment of high volcanic activity from 1800 to 1830, daily measurements of maximum and minimum temperatures, as well as precipitation totals, were considered from one of the continent's longest instrumental station at Prague-Klementinum (PK; Brázdil et al. 2012). This station is ideally located between the two tree-ring sites in the Austrian Alps and Slovakian Tatra Mountains. Combining the diurnal temperature range with daily precipitation totals (Winslow et al. 2001) and using the diurnal temperature range exclusively (Donatelli and Campbell 1998) were two methods considered to estimate changes in global radiation at PK. Comparisons against measured global radiation (19912010) and hours of sunshine (1981-2010) at PK were used to test the robustness of both methods. Similar to previous studies in the region (Trnka et al. 2005), this exercise provided very good agreement between the methods. The mean of the two methods was used to obtain monthly sums of global radiation back to 1805 (Brázdil and Budíkova 1999).

Well-mixed greenhouse gas (WMGHG) and total solar irradiance forcings (Shapiro et al. 2011), extracted from the CMIP5/PMIP3 experiments for the last millennium (Schmidt et al. 2011, 2012), together with the annual stratospheric volcanic sulfate aerosol injection, averaged over the Northern Hemisphere and the globe (Gao et al. 2008), and the different temperature records back to 1750 are shown in Fig. S6 in the supplemental material. Figure S7 in the supplemental material includes published Alpine region summer temperature variations based on 180 maximum latewood density measurement series from living and historical European larch (Larix decidua) samples in Switzerland (Büntgen et al. 2006), together with reconstructed summer precipitation totals from stable isotopic ratios using the same sub-Alpine larch trees (Kress et al. 2014) as well as estimates of springtime precipitation derived from thousands of oak (Quercus spp.) TRW series from lower-elevation forests in Germany and France (Büntgen et al. 2010, 2011).

\section{Results}

The 10 instrumental JJA temperature records share a significant fraction of interannual-to-multidecadal variability over their common period 1774-2008 (Rbar = 0.86) (Fig. 2a). With respect to the 1971-2000 mean, the combined instrumental record including Berkeley Earth, HISTALP, and other sources (Table 1) shows the first cold period in the 1770 s, followed by near-average temperatures to the end of the eighteenth century as well as the most distinct cooling in the 1810s. Slightly warmer but below average fluctuations occurred until the 1920 s, followed by a first warming into the 1940 s, after which temperatures dropped again. The most distinct warming trend started about 1980 and peaked in 2003, with limited warming afterward (Fig. 2a). The 
coldest and warmest summers captured by one of the individual instrumental records occurred in 1816 and $2003\left(-3.6^{\circ}\right.$ and $4.2^{\circ} \mathrm{C}$ departure from the $1971-2000$ climatology, respectively; Table 1), translating into a maximum amplitude of $7.8^{\circ} \mathrm{C}$ between the coldest and warmest years. The coldest and warmest years of the mean of the 10 records, however, occurred in 1821 $\left(-2.5^{\circ} \mathrm{C}\right)$ and $2003\left(3.0^{\circ} \mathrm{C}\right)$ with overall reduced amplitude. A cubic-spline smoothing with $50 \%$ frequency response cutoff at $20 \mathrm{yr}$ emphasizes decadal-scale fluctuations in the mean temperature record, including the most distinct pulse of the last $260 \mathrm{yr}$ and the modern warming trend from the 1980 s onward. The mean of the 10 instrumental (unfiltered) records explains a large portion of the variance in CEU JJA temperature (Fig. 2a). Spatial field correlation coefficients $>0.5$ cover an area between the Iberian Peninsula (British Isles) in the southwest (northwest) and the Baltic Sea (Balkans) in the northeast (southeast). This geographical pattern confirms the high level of spatial homogeneity in the mean instrumental summer temperature variability within the 30-yr reference period.

Although year-to-year agreement of the five model simulations is very low back to 1750 ( Rbar $=0.19)$, their decadal and long-term variability shows similar patterns as obtained from the instrumental data (Fig. 2b). The simulated amplitude between the warmest and coldest summers obtained from the model mean is $3.5^{\circ} \mathrm{C}$ (between $-2.3^{\circ}$ and $1.2^{\circ} \mathrm{C}$ in 1816 and 2003 , respectively), which is much smaller than the mean annual difference found in the instrumental data $\left(5.5^{\circ} \mathrm{C}\right)$. After 20 -yr lowpass filtering, the mean of the five model simulations reveals overall cooler summer conditions during the past $260 \mathrm{yr}$ in comparison to the most recent decades. The lowest temperatures occurred in the 1810s, whereas the highest values are found in the 1940s and after about 1980. Unsurprisingly, different realizations of internal climate variability in the model world are responsible for the nonsignificant amount of shared variance between the records of CEU JJA temperature over the period 1971-2000. This finding, however, has no implications for our study as we are primarily assessing the early nineteenth-century CEU summer temperature response with a particular focus on the Tambora eruption, that is, the temperature response to a punctual external climate forcing. If the ratio of forced response to internal variability is large, the model records and observations should display similar responses to the volcanic eruptions.

In contrast to the low coherency among the model simulations, the agreement between the two TRW reconstructions from Austria and Slovakia back to 1750, which share similar expressions of internal variability, is high ( $r=0.61)$ (Fig. 2c). Correlation between the Alpine region and Tatra Mountains records with JJA temperature variability across CEU is 0.72 and 0.54 (1971-2000), respectively. Both reconstructions display their most distinct cooling in the early nineteenth century between 1818 and 1821. Summer temperatures in the Alps and Tatra Mountains coincidentally start to decrease around 1800 with cooler conditions, well below the long-term average, from 1809 to 1824 . Summer temperatures in the second half of the eighteenth century, and again from the 1860 s to the 1940s, fluctuate around the 1971-2000 mean, whereas slightly cooler conditions occurred between about 1960 and 1980, followed by the recent warming trend. Coherency between the two TRW-based reconstructions is significantly higher in the early nineteenth century $(r>0.8)$ compared to around $1900(r<-0.2)$ (Fig. S3c). Increased variance in the more continental data from Slovakia translates into an overall larger amplitude of $6.4^{\circ} \mathrm{C}$, with the coldest and warmest summers in 1818 and $1939\left(-4.2^{\circ}\right.$ and $\left.2.2^{\circ} \mathrm{C}\right)$ (Table 1$)$. Under the more ocean-influenced climate across the Alpine region, the lowest and highest JJA temperatures in the Austrian data were reconstructed in 1821 and $2003\left(-3.7^{\circ}\right.$ and $\left.1.6^{\circ} \mathrm{C}\right)$, resulting in a maximum range of $5.3^{\circ} \mathrm{C}$. The mean of the two unfiltered TRW records reveals the coldest summer temperatures in 1818 $\left(-3.8^{\circ} \mathrm{C}\right)$ and the warmest in $1983\left(1.4^{\circ} \mathrm{C}\right)$. After $20-\mathrm{yr}$, low-pass filtering, the mean of the two TRW records describes rather stable temperatures before about 1800 , distinct cooler conditions in the 1810s, followed by a rapid warming until about 1830 , and a moderate increase until the 1860s. A slight long-term cooling persists until about 1980 , followed by increasing temperatures to the present. The domain covered by significant spatial field correlations of the unfiltered TRW mean falls within most of the CEU area that is represented by the instrumental record. This region includes the arcs of the Alpine region and Carpathian Mountains as well as their surrounding lowlands from France in the west, Hungary and the Ukraine in the east, Italy in the south, and Germany and Poland in the north. The coldest and warmest years, together with the lagged (1-6yr) response to the Tambora eruption of all individual instrumental records (and their mean), of all model simulations (and their mean), as well as the various TRW proxy data are summarized in Table 1.

Comparison between the instrumental, model, and proxy means reveals a coherent picture of the main features of CEU summer temperature variability over the past $260 \mathrm{yr}$ (Fig. 3a). Despite differences in the standard deviation (std dev) among the three records (std dev of $0.84^{\circ} \mathrm{C}$ in the measured and reconstructed versus std dev of $0.56^{\circ} \mathrm{C}$ in the simulated), their largest offset is found in 

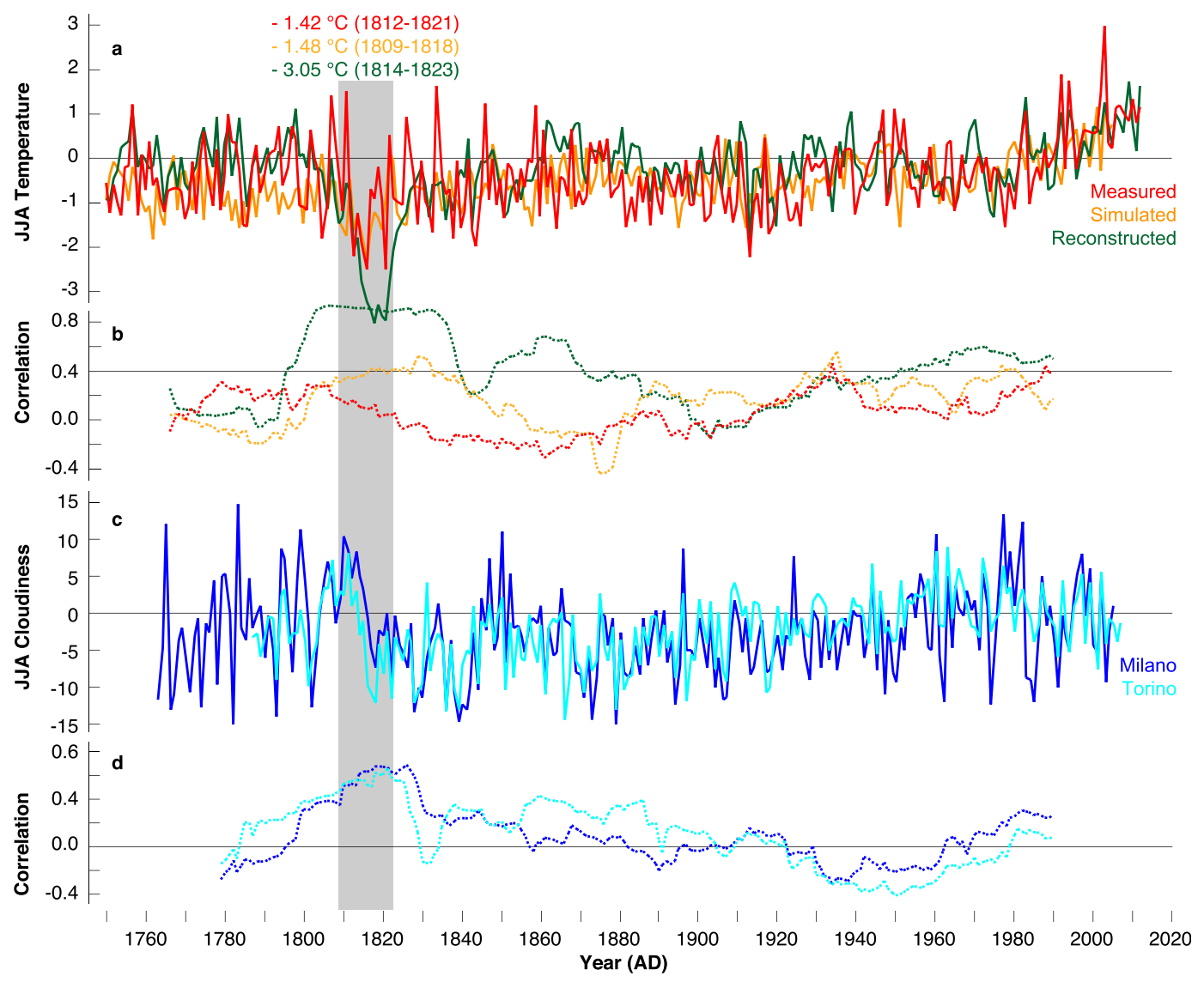

FIG. 3. (a) The mean of the 10 instrumental, 5 simulated, and 2 reconstructed (red, orange, and green) CEU summer (JJA) temperature anomalies (w.r.t. 1971-2000), with the gray vertical bar and values in degrees Celsius referring to the coldest decades of each of the three records (for data information and comparisons with volcanic forcing, see Table 1, Fig. 2, and Fig. S6). (b) The corresponding lag-1 autocorrelation functions of the mean instrumental, model and proxy records calculated over 31-yr moving intervals. (c) Anomalies of JJA cloudiness (percent of sky coverage with respect to 1971-2000) recorded in Milano and Torino back to 1763 and 1887 (blue and light blue), respectively. (d) Lag-1 autocorrelation structure of the cloud cover records computed as above.

the early nineteenth century. Following the Tambora eruption, the 10 slightly different instrumental dataset indicate cold conditions in 1816 that range between $-1.8^{\circ}$ and $-3.6^{\circ} \mathrm{C}$ with a mean of $-2.5^{\circ} \mathrm{C}$ (Table 1$)$. This depression becomes less distinct when expanding the posteruption interval. A near-similar cooling in 1816 is simulated by the model mean $\left(-2.3^{\circ} \mathrm{C}\right)$, whereas the TRW proxy mean reveals $-3.2^{\circ} \mathrm{C}$ in the summer after the Tambora eruption. The proxy data also show lower temperatures when considering more years after the eruption $\left(-3.5^{\circ} \mathrm{C}\right.$ between 1816 and 1820$)$. The coolest decade in the TRW-based reconstruction is $-3.1^{\circ} \mathrm{C}$ between 1814 and 1823 . This interval is not only considerably cooler but also occurred slightly later compared to instrumental measurements $\left(-1.4^{\circ} \mathrm{C}\right.$ from 1812 to 1821$)$ and model simulations $\left(-1.5^{\circ} \mathrm{C}\right.$ from 1809 to 1818$)$. Although the reconstructed temperatures are low during this period, particularly between 1818 and 1821, their relative drop is only slightly different from the instrumental measurements that were approximately $2.0^{\circ} \mathrm{C}$ warmer in 1811 .

This period of pronounced cooling is further expressed by a substantial increase in the first-order autocorrelation of the TRW-based reconstruction (Fig. 3b). The temporal variation in the reconstruction's lag-1 autocorrelation is more pronounced than in the other records. Significantly higher year-to-year dependency is found during the early nineteenth century when summer temperatures drop and then increase.

High-to-low-frequency changes in summer cloudiness are significantly positively correlated between Milano and Torino over their common period 1787-2005 ( $r=$ 0.69) (Fig. 3c). Most interesting is the sharp drop in temperature from 1813 to 1818 , after which cloudiness remained fairly low until about 1840 . Following some years of increased cloudiness in the 1850 s, low values 


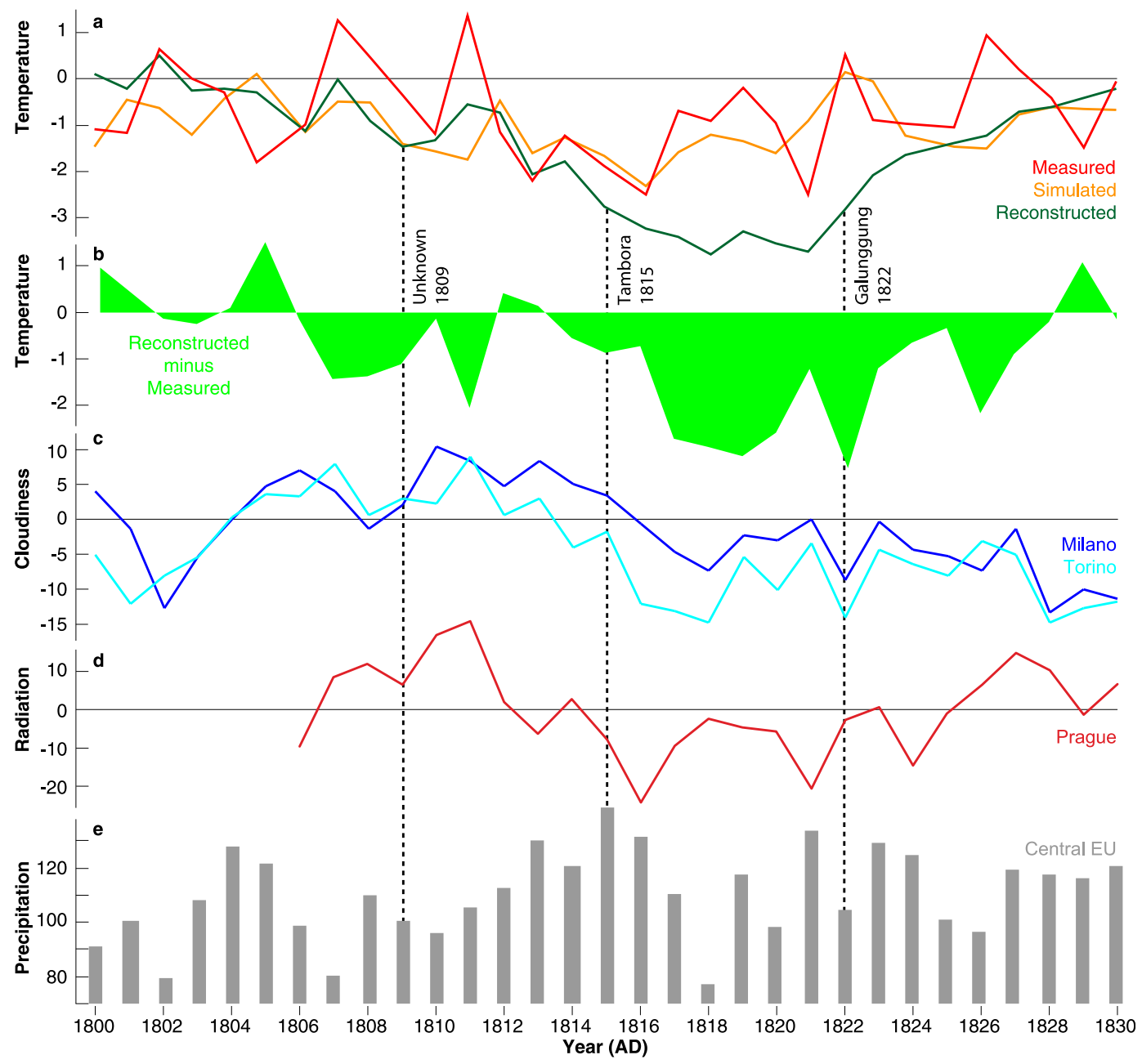

FIG. 4. (a) The mean of the 10 instrumental, 5 simulated, and 2 reconstructed (red, orange, and green) CEU summer (JJA) temperature anomalies $\left({ }^{\circ} \mathrm{C}\right.$; w.r.t. 1971-2000), (b) the corresponding proxy-target residuals (i.e., TRW minus instruments), (c) mean cloudiness recorded in Milano and Torino (\% sky coverage), (d) sum of relative solar radiation reassessed for PK (\% sky coverage with respect to 1971-2000), and (e) precipitation totals (mm) averaged over the greater Alpine region. All time series are JJA anomalies of the period 1971-2000.

persisted for several decades and cloudiness slowly increased again from about 1950 to 1980 . Like the persistence levels in the reconstructed CEU summer temperatures, the two Italian cloud cover records display their highest firstorder autocorrelation during the beginning of the nineteenth century (Fig. 3d). In the two periods of extreme positive and negative autocorrelation in these cloudiness records, their mean lag- 1 coefficients (for $\sim 1820$ is 0.6 and for $\sim 1935-1955$ is -0.4$)$ are significantly different $(p<$ 0.001 ).

A closer look at the measured, simulated, and reconstructed mean JJA temperature variability between 1800 and 1830 further distinguishes the differences between these three independent lines of paleoclimatic evidence in the Tambora posteruption period (Fig. 4a). Instrumentaland model-based summer temperatures rapidly recovered after 1816, whereas the TRW-based JJA values continued to decrease until 1821. The largest proxy deviation in summer cooling is found in 1819 and 1822 (Fig. 4b). Ring width decreased abruptly after 1814 (average ring width for $1800-1814$ is $2.05 \mathrm{~mm}$ and for $1815-1822$ is $0.66 \mathrm{~mm}$ ) and increased quickly after 1822 (average ring width for $1823-1830$ is $1.85 \mathrm{~mm}$ ). Summer cloudiness measured in Milano and Torino started to decline in 1813 and reached the lowest percentage of coverage in 1818 (Fig. 4c). Similarly, low values of cloudiness occurred in 1822 and 1828. Radiation estimates from PK dropped in 1811 and reached their summer minimum in 1816 (Fig. 4d), after which surface solar radiation fluctuated on a fairly low level until 1824. It is important to note that the estimates of summer cloudiness from Italy are noncorrelated with the radiation estimates from Prague over their common 

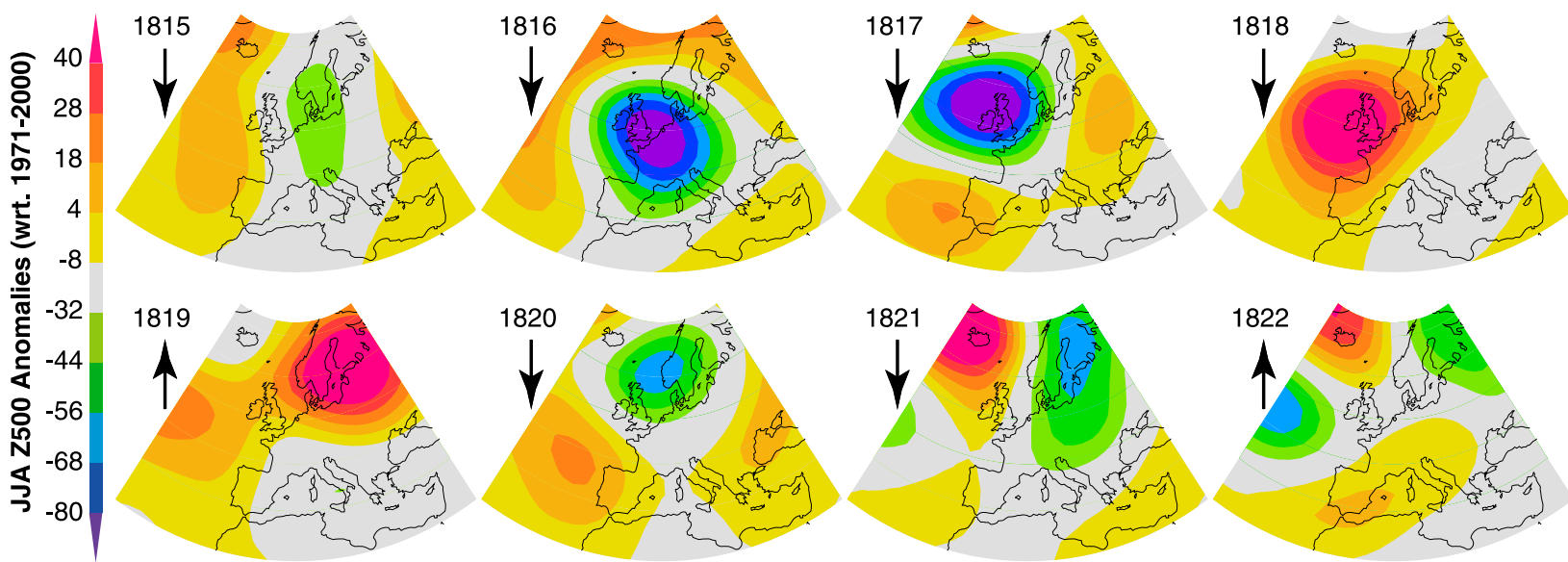

FIG. 5. Summer Z500 anomalies [in geopotential meters (gpm), with respect to the 1971-2000 climatology; data from Luterbacher et al. (2002)] over the North Atlantic/EU sector and the years 1815-22, with the black arrows indicating TRW increase or decrease relative to the previous year.

period 1806-2005 $(r=0.0)$. Precipitation totals for JJA and averaged over the greater Alpine region were particularly low in 1818 (Fig. 4e).

Although partly agreeing with the above outlined year-to-year changes in tree growth and climate, the reconstructed Z500 summer patterns reflect substantial variability over the North Atlantic/EU sector between 1815 and 1822 (Fig. 5). Slightly lower than average JJA $500-\mathrm{hPa}$ geopotential heights followed the Tambora eruption in April 1815, whereas considerably lower Z500 over western CEU characterized the 1816 summer during which TRW continued to decline. A similar pattern is found for the summer 1817 when the area of below normal pressure shifted toward the British Isles. Positive Z500 deviations over the British Isles and the Baltic Sea that occurred in 1818 and 1819, respectively, correspond to a negative TRW value in 1818 and a recovery in 1819 . The blocking Z500 values in the two summers of 1820 and 1821 coincide with low pine growth in the Austrian Alps and Slovakian Tatra Mountains (Fig. 5). Positive midtropospheric geopotential height anomalies in summer 1822 possibly triggered warmer growing season temperatures and subsequently increased TRW.

\section{Discussion}

Despite a wide range of data-related and methodologicalinduced uncertainties (see Table 1 for the spread between the different datasets), the exceptional CEU network of instrumental measurements, paleomodel simulations, and proxy reconstructions, jointly covering the past two centuries, provides independent evidence for the climatic response to the Tambora eruption in April 1815. Our new CEU summer temperature reconstruction, using 565 Swiss stone pine (Pinus cembra) ring width samples from high-elevation sites in the Slovakian Tatra Mountains and Austrian Alps, overestimates both the intensity and duration of the early nineteenth-century summer cooling by approximately $1.5^{\circ} \mathrm{C}$ averaged over $10-\mathrm{yr}$ intervals. Though measured and simulated summer temperatures already started recovering after 1816 , the coldest reconstructed conditions occurred later in 1818 and 1821. Regardless of different uncertainty levels within all proxy, target, and model data used, the reasons for the tree-ring-inherent deviation could be manifold. Hence, we first discuss the possible sources of uncertainty inherent in (section 4a) the instrumental target data, (section 4b) the climate model simulations, and (section $4 \mathrm{c}$ ) the tree-ring proxy reconstruction. Finally, we conclude our findings and provide an outlook (section $4 d$ ).

\section{a. Early instrumental uncertainty}

Early instrumental station measurements prior to the nineteenth century were specifically prone to error (Böhm et al. 2001). Although the biases due to unsheltered temperature measurements have been corrected, the adjustment itself has imposed a net warming influence on the early station data (Böhm et al. 2010). Quality constraints generally apply to all measured or observed meteorological parameters of that time, independent of the sophisticated and time-consuming quality control and homogenization process performed (Auer et al. 2007). In addition, early cloudiness records can only be interpreted as measures of the amount of sky obscured by clouds, as they lack information on both cloud type and height. In addition to the fact that historical cloud estimates are generally quite subjective, it is almost undisputable from a climatological point of view that the Milano and Torino series are not representative of conditions over the 
Alps and Tatra Mountains. There is also a lack of information of onsite precipitation. The HISTALP precipitation low-level mean has been used because of the lack of reliable measurements from higher elevations. This, and the existence of the Alpine region precipitation dipole and its trends (Brunetti et al. 2006), questions the usefulness of the low-level precipitation mean for comparison with highelevation tree-ring sites. All these reservations complicate efforts to disentangle the causes for, and consequences of, the disparity between TRW chronologies and instrumental climate records during the early nineteenth century and particularly following the Tambora eruption.

Summer temperatures, precipitation totals, global radiation, and the daily diurnal temperature range declined after the Tambora eruption. By a small measure cloudiness also dropped; however, the decline in cloudiness stayed within preeruption limits, and historical cloud observations are burdened with large uncertainties. Though Robock (2000) indicates that volcanic eruptions impact the diurnal cycle of temperature only for a few days, Auchmann et al. (2012) revealed that the frequency of clear-sky days in Prague and Geneva decreased by 5.9 and 13.7 days, respectively, in the summer of 1816 . Moreover, these authors demonstrated a drop of approximately $1^{\circ} \mathrm{C}$ in the diurnal temperature range for clear-sky days as compared to a reference, which, although at the limit of statistical significance, was likely a direct effect of volcanic aerosols. The estimated negative radiative forcing of Tambora aerosols was approximately $6-9 \mathrm{~W} \mathrm{~m}^{-2}$ for the northern midlatitudes. Nevertheless, it remains debatable if aerosol haze high above the troposphere can trigger several years of smaller diurnal temperature range. A reduced, diurnal temperature range might also be indicative of lower global radiation, which is usually indirectly related to cloud cover. A reduction of the daily temperature range at seasonal scales must therefore be interpreted with caution and cannot be directly linked to volcanism. The Tambora posteruption cloudiness measurements, serving as a proxy of cloud-related global radiation at the two Italian sites, do not show a marked difference. The combined 1815 and 1816 JJA seasons received $23 \%-25 \%$ less global radiation than average, followed by several more summers with less than average radiation. Global summer radiation estimated at PK explains $45 \%$ of the TRW variability between 1806 and 1836, an association not reached during any later period. At the same time little is known about the role of volcanic aerosols on atmospheric circulation that could, indirectly, affect local temperature variations (by advection anomalies) and precipitation regimes. All this suggests reconstructing global radiation at PK is probably a poor proxy for volcanic aerosol effects. Unfortunately, there is no alternative metric that better represents the radiative effects of an eruption on tree growth.

\section{b. Climate model uncertainty}

It should also be noted that the forced response to the Tambora eruption, represented by the model mean, agrees well with the instrumental data in the multiyear trend, but the model mean displays smaller interannual variability as expected. This is mainly because internal climate variability is partially averaged out in the mean model record. The forced response, lasting about five years across CEU, seems to agree with that modeled for the whole tropical belt (Brohan et al. 2012); however, findings from CEU represent only half of the time modeled for the global mean (Merlis et al. 2014). In any case, the lifetime of the forced response derived from the reconstruction is clearly longer than the modeled and measured estimates [cf. Wahl et al. (2014), where the late winter Tambora posteruption temperature response in western North America is reconstructed cold for eight years after the event].

\section{c. Tree-ring proxy uncertainty}

Biological persistence, resulting from various internal physiological constraints and feedbacks involved in cell formation (Fritts 1976), affects the relationship between TRW and any measured environmental forcing at various spatiotemporal scales (Frank et al. 2007). Hence, TRW chronologies can contain substantial autocorrelation resulting from the amount of the current year's accumulated photosyntate available for the following year's stem diameter growth (Tranquillini 1964; Kozlowski and Pallardy 1997). How much biologically induced autocorrelation should be preserved or removed via autoregressive modeling in the chronology building stage somewhat depends on the specific research question addressed. Nevertheless, the degree of autoregressive removal applied to TRW chronologies (ranging from more to less autocorrelation) will move the spectral properties of the inferred climatic variable from a "redder" to a "whiter" spectrum (Franke et al. 2013). Understanding the influence of biological persistence is particularly important for TRW records (Bunde et al. 2013), whereas maximum latewood density records are generally less affected (Büntgen et al. 2006). Additional uncertainty associated with the overall reconstructed temperature amplitude can originate from utilizing different proxytarget calibration intervals (Esper et al. 2005). Such error, however, usually does not appear at interannual time scales and is therefore irrelevant for the herein discussed Tambora posteruption cooling. In fact, our results do not alter when scaling over the entire twentieth century instead of shorter periods, such as 1971-2000. 
In addition, quantifying of the effects of volcanically induced, diffuse light on tree growth remains challenging (Krakauer and Randerson 2003). At issue is the degree to which increased diffusion, the surface level light scattering that may bring light deeper into the forest canopy and thereby increase potential photosynthesis (Robock 2000; Gu et al. 2003), is offset by the degree to which scattering light may decrease the initial intensity. Strong arguments for both views are made, albeit only for the latter have investigators actually tested tree-ring density measurements from boreal trees to support their conclusions (Stine and Huybers 2014; Tingley et al. 2014). Furthermore, under cloudy skies, diffuse light is often roughly isotropic (Farquhar and Roderick 2003). In contrast, after volcanic eruptions diffuse light is anisotropic, with much more forward scattering than usual. If the increased diffuse light intensities after the Tambora eruption were so extremely forward scattered, hardly brightening the sky, then the potential advantage for photosynthesis would disappear. Moreover, the role of aerosols on radiation remains elusive because sufficient data in the early nineteenth century are scarce.

Another possible explanation for the observed proxytarget offset after the Tambora eruption could be related to needle damage because of the unusually high UV-B radiation levels that typically follow large tropical volcanic eruptions (Kutterolf et al. 2013). A significant thinning of the ozone layer and a consequent increase of UV-B radiation can arise from particularly rich chlorine (Cl) and bromine (Br) emissions produced by large eruptions, such as Tambora (Self 2006). It is speculated that a highly variable stratospheric winter climate over the Arctic tends to reduce the effect of volcanic eruptions on the Northern Hemispheric ozone layer. Thus, the putative ozone reduction during the early nineteenth century might have been lower if the Tambora eruption did not coincide with exceptionally low solar activity, the Dalton Minimum (Lean et al. 1995; Wagner and Zorita 2005; Steinhilber et al. 2012), leading also to lower Arctic temperatures. The contribution of additional UV-B radiation on trees growing at high-elevation tree line ecotones under naturally high UV-B radiation levels could amplify the negative effect of postvolcanic cooling on radial growth, resulting in a larger, and longer, negative deviation in TRW.

Shorter and drier vegetation periods (Fischer et al. 2007; Trigo et al. 2009), in tandem with reduced winter precipitation and snow cover (Wegmann et al. 2014), translate into reduced springtime water supply via (a mismatch of less) snowmelt at the beginning of the (later) vegetation period when soil moisture availability is a key factor for tree-ring formation. The evidence for slightly drier conditions over Iberia after the Tambora eruption is in line with previous studies (Fischer et al. 2007; Trigo et al. 2009). The large volume of volcanic aerosols from Tambora probably nudged atmospheric winter circulation toward a more negative state of the North Atlantic Oscillation (NAO; Luterbacher et al. 1999, 2001), triggering less winter-spring precipitation totals (Rodrigo et al. 2001). Moreover, if there was less summer radiation (and less available water), tree water-use efficiency was additionally limited.

\section{d. Conclusions and outlook}

In light of the above and considering the ample uncertainty in all data used, understanding the TRW amplification of the early nineteenth-century summer cooling in CEU temperature implies the importance of alternative tree-ring parameters, such as wood density, anatomical features, isotopic ratios, and even chemical elements. For instance, maximum latewood density has been demonstrated to closely mirror abrupt temperature changes (Briffa et al. 1998). While TRW continued to decline after 1816, a rapid recovery was observed in the maximum latewood density of Alpine conifers (Büntgen et al. 2006). Independent evidence from carbon isotope variations in living and preserved larch (Kress et al. 2014), and thousands of oaks from low-elevation forests in Germany and France (Büntgen et al. 2010, 2011), suggests precipitation totals in 1822 were extremely low, confirming the instrumental record. Admittedly, our understanding of the climate signal captured in isotopic ratios, such as $\delta^{13} \mathrm{C}$, is still limited (Esper et al. 2010). High-resolution, tree-ring-based paleoclimatic research would thus benefit from incorporating aspects of plant physiology and wood anatomy because climate models alone are insufficient to solve the differences between reconstructed and measured temperatures, such as those observed after the Tambora eruption. An improved understanding of the instrumental record, together with consideration of disparate climate proxy archives not only in the early nineteenth century but also during other periods of known proxy-target offset, might help to close gaps between otherwise coherent lines of evidence.

Acknowledgments. K. Nicolussi provided TRW data from the Austrian Alps. U.B. and M.T. were supported by the Czech project "Building up a multidisciplinary scientific team focused on drought" (CZ.1.07/2.3.00/ 20.0248), and L.H. received financial support from the Eva Mayr-Stihl Foundation. M.T. was also partly funded by the Grant Agency of the Czech Republic (GA1304291S). Two anonymous referees commented on earlier versions of this manuscript. 


\section{REFERENCES}

Anchukaitis, K. J., B. M. Buckley, E. R. Cook, B. I. Cook, R. D. D'Arrigo, and C. M. Ammann, 2010: Influence of volcanic eruptions on the climate of the Asian monsoon region. Geophys. Res. Lett., 37, L22703, doi:10.1029/2010GL044843.

- , and Coauthors, 2012: Tree rings and volcanic cooling. Nat. Geosci., 5, 836-837, doi:10.1038/ngeo1645.

Auchmann, R., S. Brönnimann, L. Breda, M. Bühler, R. Spadin, and A. Stickler, 2012: Extreme climate, not extreme weather: The summer of 1816 in Geneva, Switzerland. Climate Past, $\mathbf{8}$, 325-335, doi:10.5194/cp-8-325-2012.

- and Coauthors, 2013: Impact of volcanic stratospheric aerosols on diurnal temperature range in Europe over the past 200 years: Observations versus model simulations. J. Geophys. Res. Atmos., 118, 9064-9077, doi:10.1002/jgrd.50759.

Auer, I., and Coauthors, 2007: HISTALP-Historical instrumental climatological surface time series of the greater Alpine region. Int. J. Climatol., 27, 17-46, doi:10.1002/joc.1377.

Barnett, T. P., and Coauthors, 1999: Detection and attribution of recent climate change: A status report. Bull. Amer. Meteor. Soc., 80, 2631-2659, doi:10.1175/1520-0477(1999)080<2631: DAAORC $>2.0 . \mathrm{CO} ; 2$.

Böhm, R., I. Auer, M. Brunetti, M. Maugeri, T. Nanni, and W. Schöner, 2001: Regional temperature variability in the European Alps 1760-1998 from homogenized instrumental time series. Int. J. Climatol., 21, 1779-1801, doi:10.1002/joc.689.

— , P. D. Jones, J. Hiebl, D. Frank, M. Brunetti, and M. Maugeri, 2010: The early instrumental warm-bias: A solution for long central European temperature series 1760-2007. Climatic Change, 101, 41-67, doi:10.1007/s10584-009-9649-4.

Brázdil, R., and M. Budíková, 1999: An urban bias in air temperature fluctuations at the Klementinum, Prague, the Czech Republic. Atmos. Environ., 33, 4211-4217, doi:10.1016/ S1352-2310(99)00163-6.

, P. Zahradníček, P. Pišoft, P. Štěpánek, M. Bělínová, and P. Dobrovolný, 2012: Temperature and precipitation fluctuations in the Czech Republic during the period of instrumental measurements. Theor. Appl. Climatol., 110, 17-34, doi:10.1007/ s00704-012-0604-3.

Briffa, K. R., P. D. Jones, F. H. Schweingruber, and T. J. Osborn, 1998: Influence of volcanic eruptions on Northern Hemisphere summer temperature over the past 600 years. Nature, $\mathbf{3 9 3}, 450$ 455, doi: $10.1038 / 30943$.

_- and Coauthors, 2013: Reassessing the evidence for treegrowth and inferred temperature change during the Common Era in Yamalia, northwest Siberia. Quat. Sci. Rev., 72, 83-107, doi:10.1016/j.quascirev.2013.04.008.

Brohan, P., R. Allan, E. Freeman, D. Wheeler, C. Wilkinson, and F. Williamson, 2012: Constraining the temperature history of the past millennium using early instrumental observations. Climate Past, 8, 1551-1563, doi:10.5194/cp-8-1551-2012.

Brugnara, Y., and Coauthors, 2015: A collection of sub-daily pressure and temperature observations for the early instrumental period with a focus on the "year without a summer" 1816. Climate Past Discuss., 11, 1741-1794, doi:10.5194/cpd-11-1741-2015.

Brunetti, M., M. Maugeri, T. Nanni, I. Auer, R. Böhm, and W. Schöner, 2006: Precipitation variability and changes in the greater Alpine region over the 1800-2003 period. J. Geophys. Res., 111, D11107, doi:10.1029/2005JD006674.

Bunde, A., U. Büntgen, J. Ludescher, J. Luterbacher, and H. von Storch, 2013: Is there memory in precipitation? Nat. Climate Change, 3, 174-175, doi:10.1038/nclimate1830.
Büntgen, U., D. C. Frank, D. Nievergelt, and J. Esper, 2006: Summer temperature variations in the European Alps, AD 755-2004. J. Climate, 19, 5606-5623, doi:10.1175/JCLI3917.1.

- — - R. J. Kaczka, A. Verstege, T. Zwijacz-Kozica, and J. Esper, 2007: Growth/climate response of a multi-species tree-ring network in the western Carpathian Tatra Mountains, Poland and Slovakia. Tree Physiol., 27, 689-702, doi:10.1093/ treephys/27.5.689.

—, V. Trouet, D. Frank, H. H. Leuschner, D. Friedrichs, L. Luterbacher, and J. Esper, 2010: Tree-ring indicators of German summer drought over the last millennium. Quat. Sci. Rev., 29, 1005-1016, doi:10.1016/j.quascirev.2010.01.003.

- and Coauthors, 2011: 2500 years of European climate variability and human susceptibility. Science, 331, 578-582, doi:10.1126/ science.1197175.

—, L. Wacker, K. Nicolussi, M. Sigl, D. Güttler, W. Tegel, P. J. Krusic, and J. Esper, 2014: Extraterrestrial confirmation of tree-ring dating. Nat. Climate Change, 4, 404-405, doi:10.1038/ nclimate2240.

Bürger, G., I. Fast, and U. Cubasch, 2006: Climate reconstruction

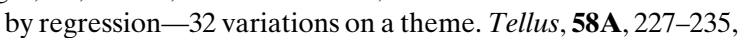
doi:10.1111/j.1600-0870.2006.00164.x.

Christiansen, B., 2011: Reconstructing the NH mean temperature: Can underestimation of trends and variability be avoided? J. Climate, 24, 674-692, doi:10.1175/2010JCLI3646.1.

Cole-Dai, J., 2010: Volcanoes and climate. Wiley Interdiscip. Rev.: Climate Change, 1, 824-839, doi:10.1002/wcc.76.

Cook, E. R., and K. Peters, 1981: The smoothing spline: A new approach to standardizing forest interior tree-ring width series for dendroclimatic studies. Tree-Ring Bull., 41, $45-53$.

- and - 1997: Calculating unbiased tree-ring indices for the study of climatic and environmental change. Holocene, 7, 361370, doi:10.1177/095968369700700314.

_ - and P. J. Krusic, 2005: ARSTAN, a tree-ring standardization program based on detrending and autoregressive time series modeling with interactive graphics. Tree-Ring Research Laboratory, Lamont-Doherty Earth Observatory, Columbia University, Earth Institute. [Available online at http://www. ldeo.columbia.edu/tree-ring-laboratory/resources/software.]

D'Arrigo, R., R. Wilson, and K. J. Anchukaitis, 2013: Volcanic cooling signal in tree ring temperature records for the past millennium. J. Geophys. Res. Atmos., 118, 9000-9010, doi:10.1002/ jgrd.50692.

de Boer, J. Z., and D. T. Sanders, 2002: Volcanoes in Human History. The Far-Reaching Effects of Major Eruptions. Princeton University Press, 320 pp.

Dobrovolný, P., and Coauthors, 2010: Monthly, seasonal and annual temperature reconstructions for central Europe derived from documentary evidence and instrumental records since AD 1500. Climatic Change, 101, 69-107, doi:10.1007/s10584-009-9724-x.

Donatelli, M., and G. A. Campbell, 1998: A simple model to estimate global solar radiation. Proc. Fifth European Society of Agronomy Congress, Nitra, Slovak Republic, European Society of Agronomy, 133-134.

Esper, J., E. R. Cook, P. J. Krusic, K. Peters, and F. H. Schweingruber, 2003: Tests of the RCS method for preserving low-frequency variability in long tree-ring chronologies. TreeRing Res., 59, 81-98.

, D. C. Frank, R. J. S. Wilson, and K. R. Briffa, 2005: Effect of scaling and regression on reconstructed temperature amplitude for the past millennium. Geophys. Res. Lett., 32, L07711, doi:10.1029/2004GL021236. 
— - - G. Battipaglia, U. Büntgen, C. Holert, K. Treydte, R. Siegwolf, and M. Saurer, 2010: Low-frequency noise in $\delta^{13} \mathrm{C}$ and $\delta^{18} \mathrm{O}$ tree ring data: A case study of Pinus uncinata in the Spanish Pyrenees. Global Biogeochem. Cycles, 24, GB4018, doi:10.1029/2010GB003772.

— Climate Change, 2, 862-866, doi:10.1038/nclimate1589.

— - U. Büntgen, J. Luterbacher, and P. J. Krusic, 2013a: Testing the hypothesis of post-volcanic missing rings in temperature sensitive dendrochronological data. Dendrochronologia, 31, 216-222, doi:10.1016/j.dendro.2012.11.002.

— L. Schneider, P. J. Krusic, J. Luterbacher, U. Büntgen, M. Timonen, F. Sirocko, and E. Zorita, 2013b: European summer temperature response to annually dated volcanic eruptions over the past nine centuries. Bull. Volcanol., 75, 736-750, doi:10.1007/s00445-013-0736-z.

Farquhar, G. D., and M. L. Roderick, 2003: Pinatubo, diffuse light, and the carbon cycle. Science, 299, 1997-1998, doi:10.1126/ science. 1080681.

Fischer, E. M., J. Luterbacher, E. Zorita, S. F. B. Tett, C. Casty, and H. Wanner, 2007: European climate response to tropical volcanic eruptions over the last half millennium. Geophys. Res. Lett., 34, L05707, doi:10.1029/2006GL027992.

Frank, D., U. Büntgen, R. Böhm, M. Maugeri, and J. Esper, 2007: Warmer early instrumental measurements versus colder reconstructed temperatures: Shooting at a moving target. Quat. Sci. Rev., 26, 3298-3310, doi:10.1016/j.quascirev.2007.08.002.

_ - J. Esper, E. Zorita, and R. J. S. Wilson, 2010: A noodle, hockey stick, and spaghetti plate: A perspective on highresolution paleoclimatology. Wiley Interdiscip. Rev.: Climate Change, 1, 507-516, doi:10.1002/wcc.53.

Franke, J., D. Frank, C. C. Raible, J. Esper, and S. Broennimann, 2013: Spectral biases in tree-ring climate proxies. Nat. Climate Change, 3, 360-364, doi:10.1038/nclimate1816.

Fritts, H. C., 1976: Tree Rings and Climate. Academic Press, 567 pp.

Gao, C., A. Robock, and C. Ammann, 2008: Volcanic forcing of climate over the past 1500 years: An improved ice core-based index for climate models. J. Geophys. Res., 113, D23111, doi:10.1029/2008JD010239.

Gärtner, H., S. Lucchinetti, and F. H. Schweingruber, 2014: New perspectives for wood anatomical analysis in dendrosciences: The GSL1-microtome. Dendrochronologia, 32, 47-51, doi:10.1016/j.dendro.2013.07.002.

Gómez-Navarro, J. J., J. P. Montávez, P. Jiménez-Guerrero, S. Jerez, R. Lorente-Plazas, J. F. González-Rouco, and E. Zorita, 2012: Internal and external variability in regional simulations of the Iberian Peninsula climate over the last millennium. Climate Past, 8, 25-36, doi:10.5194/cp-8-25-2012.

,$- \ldots$, S. Wagner, and E. Zorita, 2013: A regional climate palaeosimulation for Europe in the period 1500-1990-Part 1: Model validation. Climate Past, 9, 1667-1682, doi:10.5194/ cp-9-1667-2013.

, J. P. Werner, J. Luterbacher, S. Wagner, and E. Zorita, 2014: Establishing the skill of climate field reconstruction techniques for precipitation with pseudoproxy experiments. Climate Dyn., doi:10.1007/s00382-014-2388-x.

,,-- S. Wagner, E. Zorita, and J. Luterbacher, 2015: Precipitation in the Past Millennium in Europe-Extension to Roman Times. Springer, 133-139.

Gu, L., D. Baldocchi, S. C. Wofsy, J. W. Munger, J. J. Michalsky, S. P. Urbanski, and T. A. Boden, 2003: Response of a deciduous forest to the Mount Pinatubo eruption: Enhanced photosynthesis. Science, 299, 2035-2038, doi:10.1126/science.1078366.
Guevara-Murua, A., C. A. Williams, E. J. Hendy, A. C. Rust, and K. V. Cashman, 2014: Observations of a stratospheric aerosol veil from a tropical volcanic eruption in December 1808: Is this the Unknown $\sim 1809$ eruption? Climate Past, 10, 1707-1722, doi:10.5194/cp-10-1707-2014.

Gutiérrez, J. M., D. San-Martín, S. Brands, R. Manzanas, and S. Herrera, 2013: Reassessing statistical downscaling techniques for their robust application under climate change conditions. J. Climate, 26, 171-188, doi:10.1175/JCLI-D-11-00687.1.

Haylock, M. R., N. Hofstra, A. M. G. Klein Tank, E. J. Klok, P. D. Jones, and M. New, 2008: A European daily high-resolution gridded data set of surface temperature and precipitation for 1950-2006. J. Geophys. Res., 113, D20119, doi:10.1029/ 2008JD010201.

Hegerl, G. C., H. von Storch, K. Hasselmann, B. D. Santer, U. Cubasch, and P. D. Jones, 1996: Detecting greenhouse gasinduced climate change with an optimal fingerprint method. J. Climate, 9, 2281-2306, doi:10.1175/1520-0442(1996)009<2281: DGGICC $>2.0 . \mathrm{CO} ; 2$

, T. J. Crowley, S. K. Baum, K.-Y. Kim, and W. T. Hyde, 2003: Detection of volcanic, solar and greenhouse gas signals in paleo-reconstructions of Northern Hemispheric temperature. Geophys. Res. Lett., 30, 1242, doi:10.1029/2002GL016635.

,-- M. Allen, W. T. Hyde, H. N. Pollack, J. Smerdon, and E. Zorita, 2007: Detection of human influence on a new, validated 1500-year temperature reconstruction. J. Climate, 20, 650-666, doi:10.1175/JCLI4011.1.

— J. Luterbacher, F. González-Rouco, S. F. B. Tett, T. Crowley, and E. Xoplaki, 2011: Influence of human and natural forcing on European seasonal temperatures. Nat. Geosci., 4, 99-103, doi:10.1038/ngeo1057.

Joseph, R., and N. Zeng, 2011: Seasonally modulated tropical drought induced by volcanic aerosol. J. Climate, 24, 20452060, doi:10.1175/2009JCLI3170.1.

Körner, C., 2006: Plant $\mathrm{CO}_{2}$ responses: An issue of definition, time and resource supply. New Phytol., 172, 393-411, doi:10.1111/ j.1469-8137.2006.01886.x.

Kozlowski, T. T., and S. G. Pallardy, 1997: Physiology of Wood Plants. Academic Press, 411 pp.

Krakauer, N. Y., and J. R. Randerson, 2003: Do volcanic eruptions enhance or diminish net primary production? Evidence from tree rings. Global Biogeochem. Cycles, 17, 1118, doi:10.1029/ 2003GB002076.

Kress, A., S. Hangartner, H. Bugmann, U. Büntgen, D. C. Frank, M. Leuenberger, R. T. W. Siegwolf, and M. Saurer, 2014: Swiss tree rings reveal warm and wet summers during medieval times. Geophys. Res. Lett., 41, 1732-1737, doi:10.1002/ 2013 GL059081.

Kutterolf, S., T. H. Hansteen, K. Appel, A. Freundt, K. Krüger, W. Pérez, and H. Wehrmann, 2013: Combined bromine and chlorine release from large explosive volcanic eruptions: A threat to stratospheric ozone? Geology, 41, 707-710, doi:10.1130/G34044.1.

Lean, J., J. Beer, and R. Bradley, 1995: Reconstruction of solar irradiance since 1610: Implications for climate change. Geophys. Res. Lett., 22, 3195-3198, doi:10.1029/95GL03093.

Linderholm, H. W., and Coauthors, 2014: Growth dynamics of tree-line and lake-shore Scots pine (Pinus sylvestris L.) in the central Scandinavian mountains during the Medieval Climate Anomaly and the early Little Ice Age. Front. Ecol. Evol., 2, doi:10.3389/fevo.2014.00020.

Luterbacher, J., and C. Pfister, 2015: The year without a summer. Nat. Geosci., 8, 246-248, doi:10.1038/ngeo2404. 
C. Schmutz, D. Gyalistras, E. Xoplaki, and H. Wanner, 1999 Reconstruction of monthly NAO and EU indices back to AD 1675. Geophys. Res. Lett., 26, 2745-2748, doi:10.1029/ 1999GL900576.

_- and Coauthors, 2001: Extending North Atlantic Oscillation reconstructions back to 1500. Atmos. Sci. Lett., 2, 114-124, doi:10.1006/asle.2002.0047.

_ - and Coauthors, 2002: Reconstruction of sea level pressure fields over the eastern North Atlantic and Europe back to 1500. Climate Dyn., 18, 545-561, doi:10.1007/s00382-001-0196-6.

— D. Dietrich, E. Xoplaki, M. Grosjean, and H. Wanner, 2004: European seasonal and annual temperature variability, trends and extremes since 1500. Science, 303, 1499-1503, doi:10.1126/ science.1093877.

Mann, M. E., J. D. Fuentes, and S. Rutherford, 2012a: Underestimation of volcanic cooling in tree-ring-based reconstructions of hemispheric temperatures. Nat. Geosci., $\mathbf{5}$, 202-205, doi:10.1038/ngeo1394.

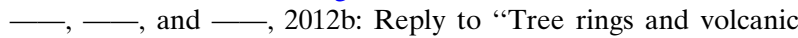
cooling." Nat. Geosci., 5, 837-838, doi:10.1038/ngeo1646.

— S. Rutherford, A. Schurer, S. F. B. Tett, and J. D. Fuentes, 2013: Discrepancies between the modeled and proxyreconstructed response to volcanic forcing over the past millennium: Implications and possible mechanisms. J. Geophys. Res. Atmos., 118, 7617-7627, doi:10.1002/jgrd.50609.

Masson-Delmotte, V., and Coauthors, 2013: Information from paleoclimate archives. Climate Change 2013: The Physical Science Basis, T. F. Stocker et al., Eds., Cambridge University Press, 383-464.

Melvin, T. M., and K. R. Briffa, 2008: A "signal-free" approach to dendroclimatic standardisation. Dendrochronologia, 26, 7186, doi:10.1016/j.dendro.2007.12.001.

— regional chronology standardisation: Part 1, Signal-free RCS. Dendrochronologia, 32, 7-20, doi:10.1016/j.dendro.2013.06.002.

Merlis, T., I. Held, G. Stenchikov, F. Zeng, and L. Horowitz, 2014: Constraining transient climate sensitivity using coupled climate model simulations of volcanic eruptions. J. Climate, 27, 7781-7795, doi:10.1175/JCLI-D-14-00214.1.

Miller, G. H., and Coauthors, 2012: Abrupt onset of the Little Ice Age triggered by volcanism and sustained by sea-ice/ocean feedbacks. Geophys. Res. Lett., 39, L02708, doi:10.1029/ 2011 GL050168.

Muller, R. A., and Coauthors, 2013: Decadal variations in the global atmospheric land temperatures. J. Geophys. Res. Atmos., 118, 5280-5286, doi:10.1002/jgrd.50458.

Oppenheimer, C., 2003: Climatic, environmental and human consequences of the largest known historic eruption: Tambora volcano (Indonesia) 1815. Prog. Phys. Geogr., 27, 230-259, doi:10.1191/0309133303pp379ra

Osborn, T. J., K. R. Briffa, and P. D. Jones, 1997: Adjusting variance for sample-size in tree-ring chronologies and other regional-mean time-series. Dendrochronologia, 15, 89-99.

PAGES 2k Consortium, 2013: Continental-scale temperature variability during the past two millennia. Nat. Geosci., 6, 339346, doi:10.1038/ngeo1797.

— 2014: A community-driven framework for climate reconstructions. Eos, Trans. Amer. Geophys. Union, 95, 361368, doi:10.1002/2014EO400001.

Robock, A., 2000: Volcanic eruptions and climate. Rev. Geophys., 38, 191-219, doi:10.1029/1998RG000054.

Rodrigo, F. S., D. Pozo-Vázquez, M. J. Esteban-Parra, and Y. Castro-Díez, 2001: A reconstruction of the winter North
Atlantic Oscillation index back to AD 1501 using documentary data in southern Spain. J. Geophys. Res., 106, 1480514 818, doi:10.1029/2000JD900728.

Rohde, R., and Coauthors, 2013: A new estimate of the average Earth surface land temperature spanning 1753 to 2011. Geoinf. Geostat., 1, 1-7, doi:10.4172/2327-4581.1000101.

Schimanke, S., H. E. M. Meier, E. Kjellström, G. Strandberg, and R. Hordoir, 2012: The climate in the Baltic Sea region during the last millennium simulated with a regional climate model. Climate Past, 8, 1419-1433, doi:10.5194/cp-8-1419-2012.

Schmidt, G. A., and Coauthors, 2011: Climate forcing reconstructions for use in PMIP simulations of the last millennium (v1.0). Geosci. Model Dev., 4, 33-45, doi:10.5194/gmd-4-33-2011.

— , and Coauthors, 2012: Climate forcing reconstructions for use in PMIP simulations of the last millennium (v1.1). Geosci. Model Dev., 5, 185-191, doi:10.5194/gmd-5-185-2012.

Self, S., 2006: The effects and consequences of very large explosive volcanic eruptions. Philos. Trans. Roy. Soc., 364A, 2073-2097, doi:10.1098/rsta.2006.1814.

Shapiro, A. I., W. Schmutz, E. Rozanov, M. Schoell, M. Haberreiter, A. V. Shapiro, and S. Nyeki, 2011: A new approach to long-term reconstruction of the solar irradiance leads to large historical solar forcing. Astron. Astrophys., 529, A67, doi:10.1051/ 0004-6361/201016173.

Shindell, D., 2014: Inhomogeneous forcing and transient climate sensitivity. Nat. Climate Change, 4, 274-277, doi:10.1038/nclimate2136.

_ , G. Schmidt, M. Mann, and G. Faluvegi, 2004: Dynamic winter climate response to large tropical volcanic eruptions since 1600. J. Geophys. Res., 109, D05104, doi:10.1029/2003JD004151.

Steinhilber, F., and Coauthors, 2012: 9,400 years of cosmic radiation and solar activity from ice cores and tree rings. Proc. Natl. Acad. Sci. USA, 109, 5967-5971, doi:10.1073/ pnas.1118965109.

Stenchikov, G., A. Robock, V. Ramaswamy, M. D. Schwarzkopf, K. Hamilton, and S. Ramachandran, 2002: Arctic Oscillation response to the 1991 Mount Pinatubo eruption: Effects of volcanic aerosols and ozone depletion. J. Geophys. Res., 107, 4803, doi:10.1029/2002JD002090.

Stine, A. R., and P. Huybers, 2014: Arctic tree rings as recorders of variations in light availability. Nature Commun., 5, 3836, doi:10.1038/ncomms4836.

Stothers, R. B., 1984: The great Tambora eruption in 1815 and its aftermath. Science, 224, 1191-1198, doi:10.1126/ science.224.4654.1191.

, 1999: Volcanic dry fogs, climate cooling, and plague pandemics in Europe and the Middle East. Climatic Change, 42, 713-723, doi:10.1023/A:1005480105370.

, 2000: Climatic and demographic consequences of the massive volcanic eruption of 1258. Climatic Change, 45, 361-374, doi:10.1023/A:1005523330643.

Taylor, K. E., R. J. Stouffer, and G. A. Meehl, 2012: An overview of CMIP5 and the experiment design. Bull. Amer. Meteor. Soc., 93, 485-498, doi:10.1175/BAMS-D-11-00094.1.

Timmreck, C., 2012: Modeling the climatic effects of large explosive volcanic eruptions. Wiley Interdiscip. Rev.: Climate Change, 3, 545-564, doi:10.1002/wcc.192.

Tingley, M. P., A. R. Stine, and P. Huybers, 2014: Temperature reconstructions from tree-ring densities overestimate volcanic cooling. Geophys. Res. Lett., 41, 7838-7845, doi:10.1002/ 2014GL061268.

Tranquillini, W., 1964: The physiology of plants at high altitudes. Annu. Rev. Plant Physiol., 15, 345-362, doi:10.1146/ annurev.pp.15.060164.002021. 
Trigo, R. M., J. M. Vaquero, M.-J. Alcoforado, M. Barriendos, J. Taborda, R. García-Herrera, and J. Luterbacher, 2009: Iberia in 1816, the year without a summer. Int. J. Climatol., 29, 99-115, doi:10.1002/joc.1693.

Trnka, M., Z. Žalud, J. Eitzinger, and M. Dubrovský, 2005: Global solar radiation in central European lowlands estimated by various empirical formulae. Agric. For. Meteor., 131, 54-76, doi:10.1016/j.agrformet.2005.05.002.

Wagner, S., and E. Zorita, 2005: The influence of volcanic, solar and $\mathrm{CO}_{2}$ forcing on the temperatures in the Dalton Minimum (1790-1830): A model study. Climate Dyn., 25, 205-218, doi:10.1007/s00382-005-0029-0.

Wahl, E., H. Diaz, J. Smerdon, and C. Ammann, 2014: Late winter temperature response to large tropical volcanic eruptions in temperate western North America: Relationship to ENSO phases. Global Planet. Change, 122, 238-250, doi:10.1016/ j.gloplacha.2014.08.005.

Wegmann, M., S. Brönnimann, J. Bhend, J. Franke, D. Folini, M. Wild, and J. Luterbacher, 2014: Volcanic influence on European summer precipitation through monsoons: Possible cause for "years without summer." J. Climate, 27, 3683-3691, doi:10.1175/JCLI-D-13-00524.1.

Wigley, T. M. L., K. R. Briffa, and P. D. Jones, 1984: On the average value of correlated time series, with applications in dendroclimatology and hydrometeorology. J. Climate Appl. Meteor., 23, 201-213, doi:10.1175/1520-0450(1984)023<0201: OTAVOC $>2.0 . \mathrm{CO} ; 2$

Winslow, J. C., E. R. Hunt, and S. C. Piper, 2001: A globally applicable model of daily solar irradiance estimated from air temperature and precipitation data. Ecol. Modell., 143, 227-243, doi:10.1016/S0304-3800(01)00341-6.

Zanchettin, D., O. Bothe, H. F. Graf, S. J. Lorenz, J. Luterbacher, C. Timmreck, and J. H. Jungclaus, 2013a: Background conditions influence the decadal climate response to strong volcanic eruptions. J. Geophys. Res. Atmos., 118, 4090-4106, doi:10.1002/jgrd.50229.

, C. Timmreck, O. Bothe, S. J. Lorenz, G. Hegerl, H. F. Graf, J. Luterbacher, and J. H. Jungclaus, 2013b: Delayed winter warming: A decadal dynamical response to strong tropical volcanic eruptions. Geophys. Res. Lett., 40, 204-209, doi:10.1029/ 2012GL054403. 